\title{
Optimal operation of a multibasin reservoir system
}

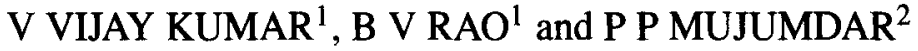 \\ ${ }^{1}$ Department of Civil Engineering, Indian Institute of Technology, \\ Bombay 400 076, India \\ ${ }^{2}$ Department of Civil Engineering, Indian Institute of Science, \\ Bangalore 560012, India \\ e-mail: cebvria@civil.iitb.ernet.in; pradeep@civil.iisc.ernet.in
}

MS received 24 November 1995

\begin{abstract}
A simulation-optimization procedure is presented for evaluating the extent of interbasin transfer of water in the Peninsular Indian river system consisting of 15 reservoirs on four river basins. A system-dependent simulation model is developed incorporating the concept of reservoir zoning to facilitate releases and transfers. The simulation model generates a larger number of solutions which are then screened by the optimization model. The Box complex nonlinear programming algorithm is used for the optimization. The performance of the system is evaluated through simulation with the optimal reservoir zones with respect to four indices, reliability, resiliency, vulnerability and deficit ratio. The results indicate that by operating the system of 15 reservoirs as a single unit the existing utilization of water may be increased significantly.
\end{abstract}

Keywords. Reservoir operation; simulation; optimization; reliability.

\section{Introduction}

The distribution of water resources is, in general, uneven in most countries. In India, the distribution is uneven both in time and space. Rainfall, which is the prime source of water in India, is mostly confined to the four monsoon months of June to September. The eight non-monsoon months receive less than $10 \%$ of the annual rainfall, as a result of which many parts of the country experience a scarcity of water during these months. The distribution of water over space is also uneven, with about $64 \%$ of the total water concentrated in the Himalayan river basins of Ganga, Indus and Brahmaputra. It is estimated that because of this uneven distribution, one-third of the country is drought-prone while about one-eighth of the country is flood-prone. To enhance the utilization of water resources through better distribution, the Government of India proposed the National Perspective Plan (NPP) for water resources development, consisting of two components, the Himalayan River Development and the Peninsular River Development (Ministry of Irrigation 1980). In 


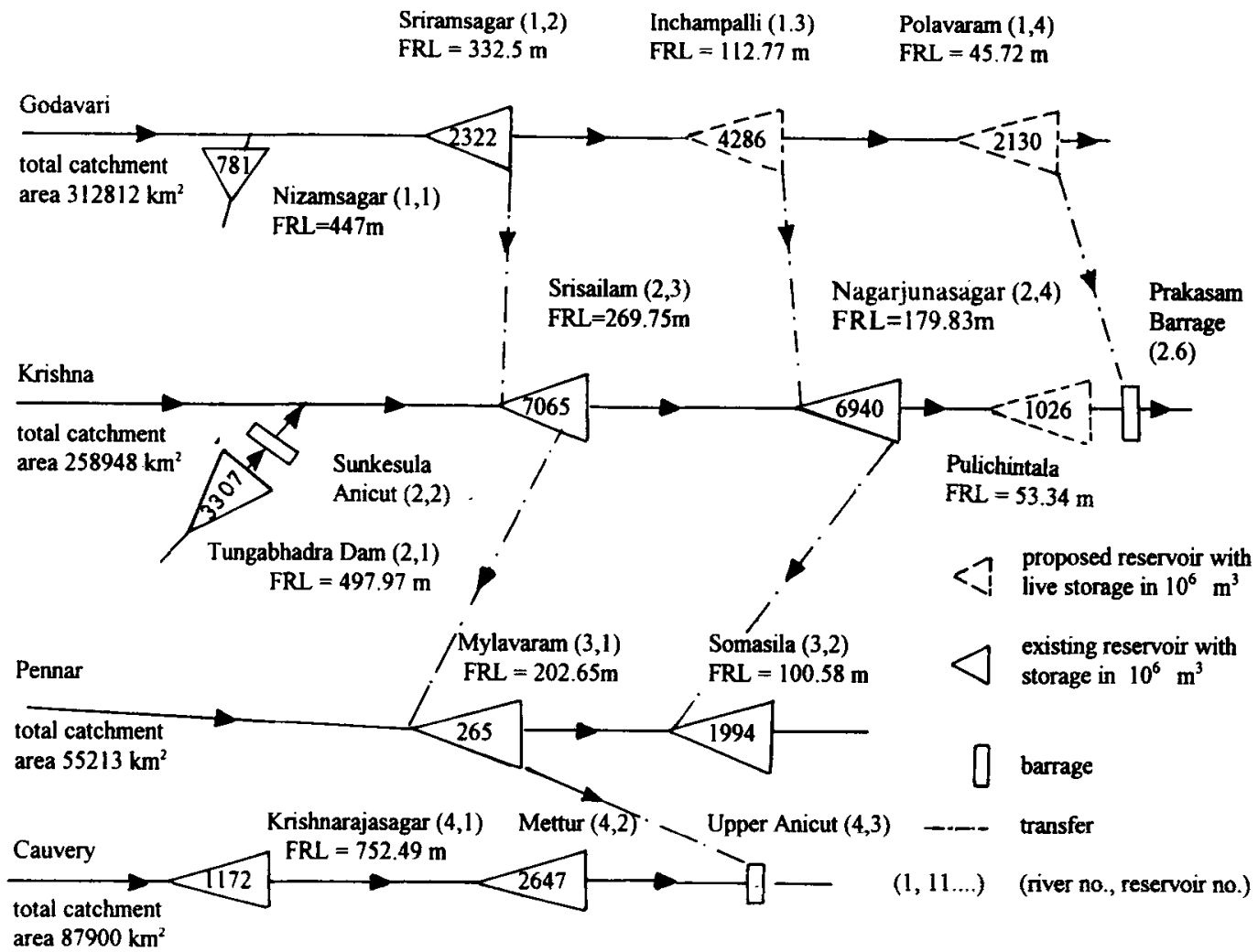

Figure 1. Schematic diagram of the Peninsular River System.

the present study, interbasin transfer of water over a major part of the peninsular river component is analysed. The system considered for analysis consists of 15 reservoirs on four rivers, Godavari, Krishna, Pennar and Cauvery, as shown schematically in figure 1. The reservoirs considered in the configuration are the Nizamsagar (NZS), Sreeramsagar (SRSP), Inchampalli (IC) and Polavaram (POL) reservoirs on the Godavari; the Tungabhadra (TB), Sunkesula (SA), Srisailam (SS), Nagarjunasagar (NS) and Pulichintala (PC) reservoirs and the Prakasam Barrage (PB) on the river Krishna; the Mylavaram (MYL) and Somasila (SMS) reservoirs on the Pennar river and the Krishnarajasagar (KRS), Mettur reservoirs (MET) and Upper Anicut (UA) on the Cauvery. For convenience in presentation, a particular reservoir is also referred by the node notation $(m, n)$ where $m$ is the basin number (with $m=1$ for the Godavari Basin and $m=4$ for the Cauvery Basin, figure 1) and $n$ is the position of the reservoir in the basin, $n=1$ for the upstream-most reservoir in that basin. For example, the reservoir $(2,3)$ denotes the Srisailam Reservoir in the Krishna Basin. Some salient features of the reservoirs are presented in table 1. Out of the 15 reservoirs, Inchampalli, Polavaram and Pulichintala are proposed reservoirs. Even though Sunkesula, Prakasam Barrage and Upper Anicut are only barrages, for the sake of computational simplicity they are also considered as reservoirs with negligible storage. All the reservoirs supply water for irrigation while some reservoirs, including the Nizamsagar, Sreeramsagar, Inchampalli; Tungabhadra, Srisailam, Nagarjunasagar and Mettur have power generation plants as well. The transfer links considered in the system are 
Inchampalli-Nagarjunasagar Dam, Polavaram-Prakasam Barrage, Srisailam-Mylavaram, Nagarjunasagar Dam-Somasila and Mylavaram-Upper Anicut. It is expected that excess water of the Godavari will be transferred to the Krishna through the first two links. These transfers will take care of some of the irrigation demands of the Nagarjunasagar and Pulichintala dams and the delta demands of the Krishna Basin at Prakasam Barrage. This enables the water saved at Srisailam to be transferred to Pennar and Cauvery through the last three links. Thus, the operation of Inchampalli, Polavaram, Srisailam and Nagarjunasagar is considered more significant compared to that of the other reservoirs.

The transfer of water among the reservoirs is by gravity, except in the case of InchampalliNagarjunasagar link where a lift of the order of $100 \mathrm{~m}$ is required. In spite of this huge lift, this link is considered an important component of the system because the high inflows joining Inchampalli can be diverted to meet the large irrigation demands at the Nagarjunasagar

Table 1. Salient features of the reservoirs of the system.

\begin{tabular}{|c|c|c|c|c|c|c|c|}
\hline $\begin{array}{l}\text { Reservoir } \\
\text { (status*) }\end{array}$ & Location & $\begin{array}{c}\text { Catchment } \\
\text { area } \\
\left(\times 10^{3} \mathrm{~km}^{2}\right)\end{array}$ & $\begin{array}{l}\text { Command } \\
\text { area } \\
\left(\times 10^{4} \mathrm{ha}\right)\end{array}$ & $\begin{array}{c}\text { Power } \\
\text { generated } \\
(\mathrm{MW})\end{array}$ & $\begin{array}{c}\text { Live } \\
\text { storage } \\
\left(\mathrm{Mm}^{3}\right)\end{array}$ & $\begin{array}{c}\text { Dead } \\
\text { storage } \\
\left(\mathrm{Mm}^{3}\right)\end{array}$ & $\begin{array}{l}\text { Period } \\
\text { of inflow } \\
\text { record }\end{array}$ \\
\hline NZS (E) & $\begin{array}{l}76^{\circ} 15^{\prime} \mathrm{E} \\
18^{\circ} 10^{\prime} \mathrm{N}\end{array}$ & 21.7 & 11.13 & 15 & 780 & 60 & $1944-86$ \\
\hline SRSP (E) & $\begin{array}{l}78^{\circ} 30^{\prime} \mathrm{E} \\
18^{\circ} 55^{\prime} \mathrm{N}\end{array}$ & 40.5 & 67.14 & 36 & 2320 & 850 & $1963-83$ \\
\hline IC (P) & $\begin{array}{l}80^{\circ} 25^{\prime} \mathrm{E} \\
18^{\circ} 37^{\prime} \mathrm{N}\end{array}$ & 42.7 & 63.58 & 975 & 4286 & 6089 & $1950-75$ \\
\hline POL (P) & $\begin{array}{l}81^{\circ} 46^{\prime} \mathrm{E} \\
17^{\circ} 13^{\prime} \mathrm{N}\end{array}$ & 37.6 & 29.14 & - & 2130 & 3381 & $1966-86$ \\
\hline TB (E) & $\begin{array}{l}76^{\circ} 18^{\prime} \mathrm{E} \\
15^{\circ} 16^{\prime} \mathrm{N}\end{array}$ & 28.8 & 34.80 & 117 & 3307 & 457 & $1951-85$ \\
\hline$S A(E)$ & $\begin{array}{l}77^{\circ} 45^{\prime} \mathrm{E} \\
15^{\circ} 48^{\prime} \mathrm{N}\end{array}$ & 36.5 & 11.30 & - & - & - & $1966-87$ \\
\hline$S S(E)$ & $\begin{array}{l}78^{\circ} 54^{\prime} \mathrm{E} \\
16^{\circ} 5^{\prime} \mathrm{N}\end{array}$ & NA & NA & 770 & 7065 & 3049 & $1964-86$ \\
\hline NS (E) & $\begin{array}{l}79^{\circ} 36^{\prime} \mathrm{E} \\
16^{\circ} 45^{\prime} \mathrm{N}\end{array}$ & 10.0 & 13.36 & 110 & 6940 & 4610 & 一 \\
\hline $\mathrm{PC}(\mathrm{P})$ & $\begin{array}{l}80^{\circ} 3^{\prime} \mathrm{E} \\
16^{\circ} 46^{\prime} \mathrm{N}\end{array}$ & 19.5 & NA & - & 1026 & 270 & $1945-81$ \\
\hline PB (E) & $\begin{array}{l}80^{\circ} 55^{\prime} \mathrm{E} \\
16^{\circ} 35^{\prime} \mathrm{N}\end{array}$ & 16.6 & 48.56 & - & - & - & $1945-81$ \\
\hline MYL (E) & $\begin{array}{l}78^{\circ} 20^{\prime} \mathrm{E} \\
14^{\circ} 51^{\prime} \mathrm{N}\end{array}$ & 19.2 & 1.95 & - & 266 & 17 & 1969-86 \\
\hline SMS (E) & $\begin{array}{l}79^{\circ} 18^{\prime} \mathrm{E} \\
14^{\circ} 29^{\prime} \mathrm{N}\end{array}$ & 29.4 & 16.39 & - & 1994 & 214 & 1929-82 \\
\hline
\end{tabular}


Table 1. Continued.

\begin{tabular}{lccccccc}
\hline $\begin{array}{l}\text { Reservoir } \\
\text { (status*) }\end{array}$ & Location & $\begin{array}{c}\text { Catchment } \\
\text { area } \\
\left(\times 10^{3} \mathrm{~km}^{2}\right)\end{array}$ & $\begin{array}{c}\text { Command } \\
\text { area } \\
\left(\times 10^{4} \mathrm{ha}\right)\end{array}$ & $\begin{array}{c}\text { Power } \\
\text { generated } \\
(\mathrm{MW})\end{array}$ & $\begin{array}{c}\text { Live } \\
\text { storage } \\
\left(\mathrm{Mm}^{3}\right)\end{array}$ & $\begin{array}{c}\text { Dead } \\
\text { storage } \\
\left(\mathrm{Mm}^{3}\right)\end{array}$ & $\begin{array}{c}\text { Period } \\
\text { of inflow } \\
\text { record }\end{array}$ \\
\hline KRS (E) & $\begin{array}{l}76^{\circ} 31^{\prime} \mathrm{E} \\
12^{\circ} 25^{\prime} \mathrm{N}\end{array}$ & 10.6 & 11.36 & - & 1172 & 125 & $1934-86$ \\
MET (E) & $\begin{array}{l}77^{\circ} 55^{\prime} \mathrm{E} \\
11^{\circ} 55^{\prime} \mathrm{N}\end{array}$ & NA & 12.14 & 200 & 2647 & 553 & $1966-87$ \\
UA (E) & $78^{\circ} 50^{\prime} \mathrm{E}$ & $\mathrm{NA}$ & 44.52 & - & - & - & $1966-87$ \\
\hline
\end{tabular}

*Status: (E): Existing (P): Proposed

Dam. Apart from the transfer links proposed in the configuration, the demands of the existing century-old link between Krishna and Pennar called the Kurnool-Cuddappah canal are also protected. The historic data of monthly inflows, salient features and demands at all the reservoirs are obtained from the Central Water Commission and various State Government agencies.

In modelling complex multireservoir systems, one methodology often employed is screening of the potential alternatives first by an optimization model and evaluating the performance of the system with these alternatives in detail by a simulation model (e.g. Joeres et al 1971; Jacoby \& Loucks 1972; Chaturvedi \& Srivastava 1981). For a complex water resources system, such as the one considered in this study, it is practically impossible to represent all the system features in an optimisation model. On the other hand, simplifying the formulation to make the problem computationally tractable can lead to planning errors. It is therefore necessary to carry out an initial simulation to reduce the size of the optimization model. Some examples of such studies may be found in the literature (Sigvaldason 1976; Chung \& Helweg 1985; Simonovic 1987; Razavian et al 1990; Kuo et al 1990).

In the present study, the concept of reservoir zoning (Beard 1967; Sigvaldason 1976) is adopted for identifying the limits for releases and interbasin transfers. Each reservoir is divided into four storage zones as shown in figure 2 . The four storage zones are minimum storage $\left(S_{\mathrm{MNN}}\right)$, maximum storage $\left(S_{\mathrm{MAX}}\right)$, releasable storage $\left(S_{\mathrm{REL}}\right)$ and transferable storage $\left(S_{\text {TRA }}\right)$.

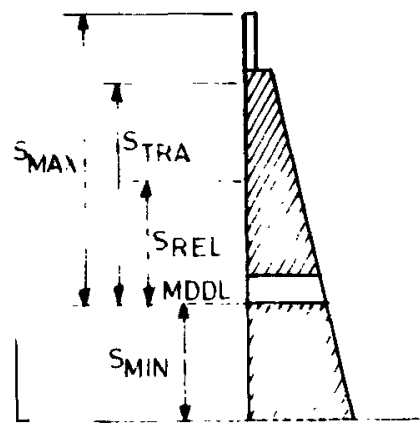

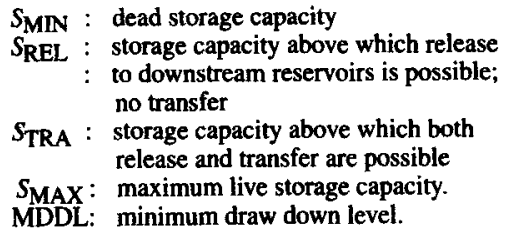

Figure 2. Reservoir zoning. 
The objectives of the systems analysis carried out in the study are: (i) to delineate the different storage zones at each reservoir, (ii) to examine the potential of the transfer links envisaged in meeting the existing demands in the command areas of the reservoirs and (iii) to quantify the extent to which the water availability can be increased at some important reservoirs through an optimal operation of the system. This study is carried out in two stages: In the first stage, a detailed simulation model is developed and a large number of solutions are generated. The sensitivity of the system performance to changes in priorities, storage zone levels, demands and operational strategies is examined in this stage, and ranges of the different parameters for which the system performance is sensitive are identified. This stage generates a huge database to supply some of the inputs required in the second stage. In the second stage, a nonlinear optimization problem is solved to identify the best solution within the range identified in the first stage for each parameter. The solution of the optimization model specifies the zone levels at each reservoir, the extent to which the water availability can be raised at a reservoir and the extent of possible interbasin transfers. Details of the two models are discussed in the following sections.

\section{Simulation model}

The simulation model generates a large number of solutions corresponding to various levels of the four storage zones. The significance of these zones for the operation of the reservoirs is as follows. The minimum storage ( $\left.S_{\mathrm{MIN}}\right)$ is the dead storage capacity and the maximum storage $\left(S_{\mathrm{MAX}}\right)$ is the live storage capacity of a reservoir. Both these zones ( $S_{\mathrm{MIN}}$ and $S_{\mathrm{MAX}}$ ) are known constants for every reservoir. The other two storage zones, the releasable storage $\left(S_{\mathrm{REL}}\right)$ and the transferable storage $\left(S_{\mathrm{TRA}}\right)$ facilitate releases to downstream reservoirs and transfers to reservoirs of other basins respectively. By definition, if the storage at a reservoir, after satisfying its own demands in a period, is more than $S_{\mathrm{REL}}$, then the excess water over $S_{\text {REL }}$ can be released to meet the deficits of the downstream reservoirs of the same basin. Similarly, after meeting the basin requirements in a period, if the storage is more than $S_{\text {TRA }}$, then the excess water over $S_{\text {TRA }}$ can be transferred, if a link exists, to meet the deficits of reservoirs of the other basins. There are, thus, three purposes for which water from a reservoir in the system can be utilized. In order of priority, they are (a) to meet the demands from the command area of the reservoir itself, (b) to meet completely or partially the demands of the immediate downstream reservoir in the same river basin, and (c) to meet completely or partially the demands at a reservoir in another basin through transfer links. In this study a 'diversion' from a reservoir is defined as the water supplied to meet its own demands, a 'release' as the water supplied to meet the deficits at the downstream reservoirs of the same basin, and a 'transfer' as the water supplied to meet the deficits at the reservoirs of other basins.

The aim of the simulation model is to examine the performance of the system for several alternatives of storage zones and to identify an initial value and a range for each parameter for use in optimization subsequently. The flow chart of the model is given in figure 3 . At the beginning of the period, the deficits, if any, are determined at each reservoir after accounting for diversion. The deficit at a reservoir is reduced or eliminated completely either by release from an upstream reservoir or through transfer from another basin (if 


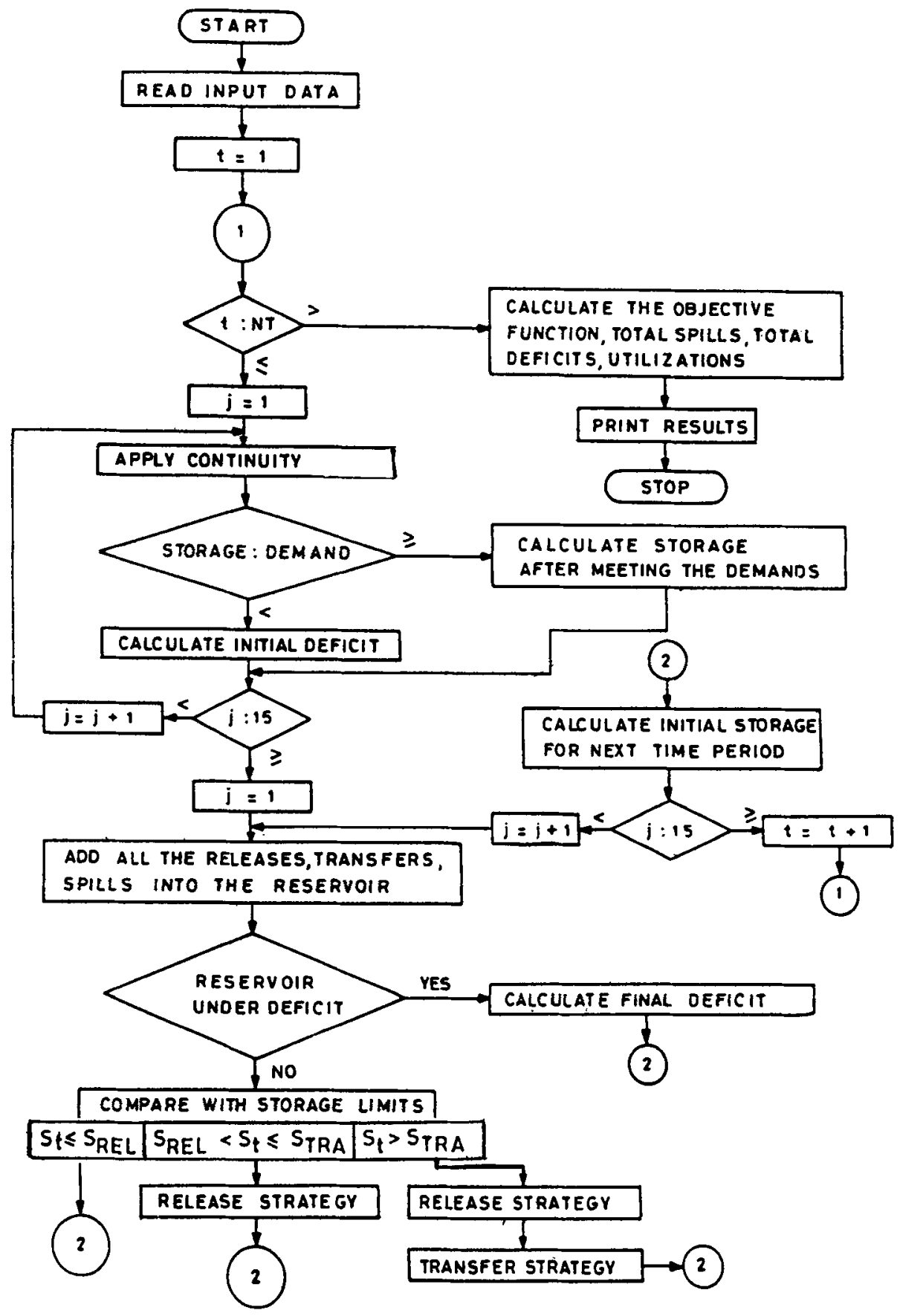

Figure 3. Flow chart of the simulation model. 
such a link exists), or both. The amounts of release and transfer are decided based on the available storage in a reservoir after meeting the demand from its own catchment. Based on the priorities listed earlier, release and transfer policies are formulated. The releases and transfers are made till either the available excess water is exhausted or there is no need for any more release or transfer.

\subsection{Release and transfer policies}

The release policy aims at the minimisation of spills out of the system. The downstream reservoirs are depleted first before withdrawing water from upstream reservoirs. The release policy is invoked at a reservoir $\mathrm{M}$, when the available storage, after accounting for diversions to meet the demands at the reservoir itself, is more than $S_{\mathrm{REL}}$. Release $R_{t}^{\mathrm{M}, \mathrm{L}}$ from the reservoir $M$ to a downstream reservoir $L$, if exists, is given by

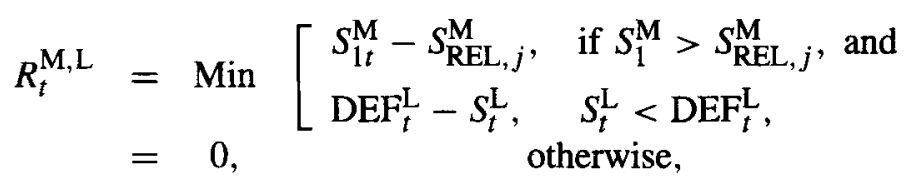

where $S_{1 t}^{\mathrm{M}}$ is the storage at reservoir $\mathrm{M}$ during period $t$ after accounting for its own demand $d_{t}^{\mathrm{M}}$, releases and transfers committed to the reservoir $\mathrm{M}$ from other reservoirs and release commitments made from the reservoir $\mathrm{M}$ to other reservoirs downstream of $\mathrm{M} . S_{t}^{\mathrm{L}}$ is the storage at the reservoir $\mathrm{L}$ after accounting for all transfers and releases from other reservoirs downstream of $\mathrm{M}$, committed to it during the period and $S_{\mathrm{REL}, j}^{\mathrm{M}}$ is the releasable storage for the reservoir $M$ in season $j$ to which the period $t$ belongs. In this study a year is divided into two seasons, the monsoon season $(j=1)$, comprising months June to November and the non-monsoon season $(j=2)$, comprising months December to May. When at reservoir $\mathbf{M}$, the releases from the reservoir are computed for all the downstream reservoirs starting with reservoir $\mathbf{M}+1$ and proceeding downstream till either the releasable amount of water is exhausted at reservoir $\mathbf{M}$ or the demands at all reservoirs of the basin are met. For example, if for the reservoir $(1,2)$ in figure 1 , excess water is available and if an initial deficit exists at $(1,4)$ then this deficit is met by a release from $(1,3)$ if possible and a release from $(1,2)$ is made only if the release from $(1,3)$ fails to meet the deficit at $(1,2)$.

The transfer policy is similar to the release policy. The deficit at a reservoir, after accounting for diversion from the particular reservoir itself and releases from reservoirs in its own basin, is met either partially or fully by transfer from reservoirs of other basins if a transfer link exists. The amount of water transferred, $T_{t}^{\mathrm{M}, \mathrm{P}}$, from reservoir $\mathrm{M}$ of a basin to reservoir $\mathrm{P}$ of another basin in period $t$, when a transfer link exists, is given by,

$$
\begin{aligned}
& T_{t}^{\mathrm{M}, \mathrm{P}}=\operatorname{Min}\left[\begin{array}{ll}
S_{2 t}^{\mathrm{M}}-S_{\mathrm{TRA}, j}^{\mathrm{M}}, & \text { if } S_{2 j}^{\mathrm{M}}>S_{\mathrm{TRA}, t}^{\mathrm{M}}, \text { and } \\
\mathrm{DEF}_{t}^{\mathrm{P}}-S_{t}^{\mathrm{P}}, & S_{t}^{\mathrm{P}}<\mathrm{DEF}_{t}^{\mathrm{P}}
\end{array}\right. \\
& =0, \quad \text { otherwise. }
\end{aligned}
$$

where $S_{2 t}^{\mathrm{M}}$ is the storage available at reservoir $\mathrm{M}$ after accounting for the diversion and release, $S_{\mathrm{TRA}, j}^{\mathrm{M}}$ is the transferable storage in reservoir $\mathrm{M}$ for the season $j$ to which the period $t$ belongs, $S_{t}^{\mathrm{P}}$ is the storage at the reservoir $\mathrm{P}$ after accounting for diversion and release 
and transfers committed to it for the period (by other reservoirs during the computations prior to those for reservoir $\mathrm{M}$ ), and $\mathrm{DEF}_{t}^{\mathrm{P}}$ is the deficit at the reservoir $\mathrm{P}$ in period $t$, corresponding to the storage $S_{t}^{\mathrm{P}}$.

At any reservoir if a deficit exists even after the promised releases from reservoirs of the same basin, the deficit is met partially or completely with transfer from other basins. This transfer is not necessarily through a direct link between the two reservoirs and may be routed through other reservoirs. For example, if reservoir $(2,6)$ is under deficit, then, in simulation, a transfer is first tried from $(1,4)$ to meet the deficits at $(2,6)$ and, only if this transfer does not meet the deficits completely, is a transfer made from $(1,3)$, routed either through $(2,4)$ or through $(1,4)$ or both. Also, the hierarchy of the downstream-most reservoir to the upstream-most reservoir is maintained while examining the transfers; that is, a transfer from an upstream reservoir is considered only if there is no transfer link from a downstream reservoir, or if the transfer from the downstream reservoir is inadequate. Appropriate loss coefficients are incorporated for diversion, release and transfers from a reservoir.

A major objective of the interbasin transfers in this study is to examine the extent to which the existing utilizations could be raised. Two parameters, INCR1 for the monsoon season (June-November) and INCR2 for the non-monsoon season (December-May), are introduced as multiplying factors to the irrigation demands in the corresponding periods. The power generation demands are kept at their existing level. Thus, the extent to which the command areas can be increased at every reservoir as a result of the interbasin transfer is evaluated. The information on the extent of additional land that can be brought under irrigation is not available. The present study is carried out in the absence of such information and the INCR1 and INCR2 parameters are increased on the basis of their effect on the performance of the system as a whole. In case of reservoirs on the Godavari and the Krishna basins, however, both these parameters are restricted to 2.0 as the command areas are generally well developed at these reservoirs.

A sensitivity analysis with 15 (one per reservoir) each of INCR1, INCR2, $S_{\mathrm{REL}, 1}, S_{\mathrm{REL}, 2}$, $S_{\text {TRA, } 1}$ and $S_{\text {TRA,2 }}$ parameters is carried out to identify the most productive range for each parameter and to evaluate the performance of the system under various alternatives. The existing demands in both the periods are protected and care is taken to see that, as far as possible, the deficits at any reservoir in any period are below or in the vicinity of $10 \%$ of the total demands. If there is a conflict between water for irrigation and power generation, diversions for irrigation are given preference as all the reservoirs are primarily operated for irrigation. The performance of the system with different alternatives are compared with an objective function which maximises the utilization of resources while penalising the deficits. In the case of a trade-off among different reservoirs, the reservoirs on Cauvery and Pennar, for example, are given preference as the command areas are underdeveloped in these basins.

Statistical analysis carried out to fit theoretical probability distributions to the historic data at the reservoir sites reveal that in 149 of the 168 data sets (corresponding to 14 reservoirs and 12 months) the log normal distribution fits the data set reasonably well. For the purpose of simulation, synthetic streamflows generated for a longer period with logarithmic transformed data are used. The Thomas-Fiering model, incorporating corrections suggested by Matalas (1967) is used for synthetic generation. A limitation of this model is 
Table 2. Prominent transfers for 50 -year simulation analysis.

Units: million cubic metres; figures in brackets indicate the number of times the transfer has taken place in a 50 -year period

\begin{tabular}{lcccccccc}
\hline & From & \multicolumn{3}{c}{ Inchampally } & \multicolumn{3}{c}{ Polavaram } & \multicolumn{3}{c}{ Srisailam } \\
\cline { 2 - 8 } Month & To & NS & PC & PB & PB & MYL & SMS & UA \\
\hline Jun & & - & $257(4)$ & $635(5)$ & $5302(18)$ & $223(15)$ & $48(2)$ & $18259(30)$ \\
Jul & & $4216(14)$ & $13204(29)$ & $580(3)$ & $17941(29)$ & $1951(41)$ & $1967(13)$ & $102362(49)$ \\
Aug & & $39495(27)$ & $3470(10)$ & $432(1)$ & $13510(22)$ & $1886(44)$ & $3973(13)$ & $81759(46)$ \\
Sep & $13110(14)$ & $3626(12)$ & $1126(3)$ & $25430(43)$ & $1026(23)$ & $1608(7)$ & $37612(44)$ \\
Oct & - & $937(3)$ & $4296(10)$ & $19605(35)$ & $585(15)$ & $1079(6)$ & - \\
Nov & - & $210(3)$ & $5886(20)$ & $9421(27)$ & $511(13)$ & $405(3)$ & - \\
Dec & - & $702(6)$ & $2644(18)$ & $2010(13)$ & $490(14)$ & $917(6)$ & - \\
Jan & - & - & - & $600(8)$ & $702(18)$ & $732(7)$ & $11842(43)$ \\
Feb & - & - & - & $544(8)$ & $578(19)$ & $1098(9)$ & $28686(42)$ \\
Mar & - & - & - & $2293(19)$ & $661(18)$ & $768(7)$ & $34481(38)$ \\
Apr & - & - & - & $345(2)$ & $510(15)$ & $1188(8)$ & $2594(31)$ \\
May & - & - & - & $34(2)$ & $340(11)$ & $226(6)$ & - \\
\hline
\end{tabular}

that it is a single-site model and therefore does not preserve the cross correlations among different rivers. A better approach would be to use one of the multi-site models (e.g., the MARMA type of models).

The primary purpose of the simulation is, thus, to prepare ground for more accurate and more systematic optimization. The parameters to which the system performance is sensitive, their possible ranges and the associated increments by which the parameters should be varied in the optimization are all identified by the simulation analysis. Table 2 gives summary results of one of the simulation runs for a 50-year period. The table shows the transfers made through various links for a set of given values of storage zones and feasible values of INCR1 and INCR2.

\section{Optimization model}

Within the range identified for a particular parameter, an optimal value of the parameter is determined by solving an optimization model. The parameters for which optimal values are sought are, $S_{\mathrm{REL}, 1}$ and $S_{\mathrm{REL}, 2}$, the releasable storage limits for the monsoon and nonmonsoon seasons respectively, $S_{\mathrm{TRA}, 1}$ and $S_{\mathrm{TRA}, 2}$, the transferable storage limits for the two seasons and INCR1 and INCR2, the factors by which the irrigation potential may be increased for the two seasons. A variation in any one of these parameters at a critical reservoir will affect the entire system. It is therefore necessary to identify the optimum values of these parameters for the fixed release and transfer policies discussed earlier. The optimization model is formulated as follows:

$$
\operatorname{Max} . \sum_{k} \sum_{t} \alpha U_{t}^{k}-\beta D_{t}^{k}
$$


subject to:

(i) Diversion policy,

$$
\begin{aligned}
\mathrm{DIV}_{t}^{k} & =d_{t}^{k} \quad \text { if, } S_{i t}^{k}+I_{t}^{k}>d_{t}^{k} \\
& =S_{i t}^{k}+I_{t}^{k} \text { otherwise. }
\end{aligned}
$$

(ii) Release policy, (1)

(iii) Transfer policy, (2)

(iv) Definition constraints:

$$
\begin{aligned}
D_{t}^{k} & =d_{t}^{k}-U_{t}^{k}, \quad \text { if positive, } \\
& =0, \quad \text { otherwise. } \\
U_{t}^{k} & =\mathrm{DIV}_{t}^{k}+R_{t}^{k}+T_{t}^{k} \\
d_{t}^{k} & =\operatorname{INCR} 1^{k}\left(\mathrm{DEM}_{t}^{k}\right), \quad \forall t \in \text { monsoon season. } \\
& =\mathrm{INCR} 2^{k}\left(\mathrm{DEM}_{t}^{k}\right), \quad \forall t \in \text { nonmonsoon season, }
\end{aligned}
$$

(v) Storage continuity, physical constraints and non-negativity of the variables; and

(vi) Consuraints due to priorities discussed in the simulation model.

In this model, $\alpha$ represents the economic value of the water actually utilized. $\beta$ represents the penalty (loss) associated with not meeting the demands. Both $\alpha$ and $\beta$ are complex functions of operational priorities, the purpose for which the water is used, market conditions and even the societal preferences. Representing all these factors into single economic coefficients is therefore a gross approximation of the economic process. However, the purpose of the present study being to examine the physical distribution of water in the system, this approximation is deemed justifiable.

For solving the optimization model, the Box complex algorithm (Box 1965) is used. The algorithm solves the following general problem,

$$
\text { Minimise } f\left(x_{1}, x_{2}, \ldots, x_{n}\right),
$$

subject to constraints of the form $g_{k} \leq x_{k} \leq h_{k}, k=1, \ldots, m$, where $x_{n+1} \cdots x_{m}$ are functions of $x_{1} \cdot x_{n}$ and the lower and upper constraints $g_{k}$ and $h_{k}$ respectively are either constants or functions of $x_{1} \cdots x_{n}$.

The algorithm is likely to find a lower optimum (for a minimization problem) than other similar algorithms if the permissible region contains several local peaks, as it does not depend much on the initial point supplied (Box 1965). An IMSL subroutine, BCPOL, that minimises a function of $n$ variables subject to bounds on the variables using a direct search complex method is used. In this routine, the function to be minimised may be given as a user-supplied subroutine. In the present case, the search algorithm determines improved values for each of the parameters based on the objective function and direction of movement in the previous trials. Corresponding to this new set of parameter values, the objective function value is determined through the simulation model. Along with the $\mathbf{3 0}$ 
Table 3. Summary results of the optimization.

\begin{tabular}{lcrrr}
\hline Reservoir & $\begin{array}{r}S_{\mathrm{REL}, 1} \\
\left(\mathrm{Mm}^{3}\right)\end{array}$ & $\begin{array}{c}S_{\mathrm{REL}, 2} \\
\left(\mathrm{Mm}^{3}\right)\end{array}$ & $\begin{array}{r}S_{\mathrm{TRA}, 1} \\
\left(\mathrm{Mm}^{3}\right)\end{array}$ & $\begin{array}{r}S_{\mathrm{TRA}, 2} \\
\left(\mathrm{Mm}^{3}\right)\end{array}$ \\
\hline$(1,3)$ & 1588.34 & 2793.47 & 2373.59 & 3873.01 \\
$(1,4)^{*}$ & - & - & 162.91 & 1232.78 \\
$(2,3)$ & 1134.35 & 189.32 & 1521.93 & 417.15 \\
$(2,4)$ & 895.74 & 1525.69 & 685.60 & 417.67 \\
\hline
\end{tabular}

* There is no reservoir downstream of $(1,4)$, Release not possible.

INCR parameters, only 14 of the 60 storage parameters are subjected to optimization as the system performance is found to be less sensitive to the other storage parameters in the initial simulation runs. Optimization is carried out for a period of only one year. In India, flows at $75 \%$ exceedence probability are generally considered for planning purposes. A critical sequence of flows with $75 \%$ exceedence probability is therefore used in the model. Since only a one-year period is considered for optimization, choice of the initial state of the system is a very important exercise; the most likely range for the initial state of each reservoir of the system as obtained from a statistical analysis of the large number of simulation results is used for the purpose. The initial values and the range for search required as an input by the optimization algorithm for each of the parameters is also obtained from the simulation results. Since the optimal solution is dependent on the initial guesses, successive runs are carried out by specifying the optimal values of the parameters of one run as the initial guesses for the next run and modifying the ranges accordingly. This process is continued till analyses with different initial guesses result in approximately the same solution. In the present case, the convergence was achieved within 8 such cycles. Table 3 gives the optimal storage zone levels obtained by this procedure with the inflows at $75 \%$ exceedence probability. These storage zones in conjunction with the various policies adopted resulted in a significant increase in the water availability in the Cauvery and Pennar basins without affecting the existing demands at the other basins.

\section{Performance evaluation}

The performance of the system operation with the optimal solution is examined over a long period by simulation analysis using four performance indices, viz., reliability $(\rho)$, resiliency $(\gamma)$, vulnerability $(\nu)$ and deficit ratio $(\delta)$.

In defining the reliability and resiliency, the concept of 'Failure index' suggested by Fiering (1982) that incorporates both the frequency and severity of failure is used. According to this, a full failure is the one when even $75 \%$ of the demands are not met and smaller failures are measured with the expression $\Delta_{i} / 0.25 T_{i}$, where $\Delta_{i}$ is the deficit and $T_{i}$ is the target: $0 \leq \Delta_{i} / 0.25 T_{i} \leq 1$. The failure index $F$ is calculated as the ratio of the sum of all the failures to the total number of periods. The reliability $(\rho)$ is defined in this study as $1-F$. The resiliency $(\gamma)$ is defined as the ratio of the number of transitions from a failure state to a satisfactory state and the total number of failures. By incorporating the 
Table 4. Summary of the yearly performance indices for the system.

\begin{tabular}{ll}
\hline Reliability $(\rho)$ & 0.946 \\
Resiliency $(\gamma)$ & 0.680 \\
Vulnerability $(\nu)$ & 0.474 \\
Deficit ratio $(\delta)$ & 0.014 \\
\hline
\end{tabular}

concept of failure index, the improvement in the performance from a larger failure to a smaller failure is also accounted for in the definition of resiliency. Thus, these two indices ( $\rho$ and $\gamma$ ) are defined in a slightly different way as compared to the definitions suggested by Hashimoto et al (1982). Vulnerability (v) is defined as the ratio of the largest deficit during the period of operation to the corresponding demand at the reservoir. The deficit ratio $(\delta)$, defined as the ratio of the total deficit to the total demand is used to measure the effect of cumulative deficit. The performance of the system should desirably result in high reliability and resiliency and low vulnerability and deficit ratio.

A 500-year simulation is carried out to estimate the performance indices using the synthetic streamflow sequences. The indices are estimated for each reservoir and the system as a whole in each month and over the whole year. In addition, reliability of two of the prominent transfer links, the Polavaram $(1,4)$ - Prakasam Barrage $(2,6)$ and the Srisailam $(2,3)$ - Upper Anicut $(4,3)$ links, is also estimated with 'committed transfers' as obtained from optimization analysis. The results of the performance of the system as a unit over the entire period are given in table 4 . The results of the monthly performance indices of the system and the yearly performance indices of the reservoirs are given in table 5 and table 6 respectively.

It must be noted that the performance values given in these tables correspond to the use of the optimal storage zone levels and increased irrigation supplies specified by the solution of the optimization model. It is observed that although the reliability of meeting the increased demands is quite high, the vulnerability of the system to large deficits is high too, signifying that in the few periods where failure occurs, a large deficit may result. It is also important to note that none of these criteria are explicitly included in the optimization and therefore they are not, in fact, the 'optimum' values of the system performance. They are, however, indicators of how the system is likely to perform under the 'optimal' operation over a long period of time, when a sequence of inflows used in the simulation is, in fact, realized.

\section{Conclusions}

In this study, a simulation-optimization approach is used to analyse the complex multibasin, multireservoir Peninsular Indian river system. The simulation model of the type presented in this study is essential in order to build a database of various operating strategies. The sensitive parameters selected with a large number of simulation runs are optimized over a wide range of alternatives and a solution of the system operation is obtained with inflows at a specified probability of exceedence. The performance of the system over a long period with this solution is analysed again by a simulation analysis. 

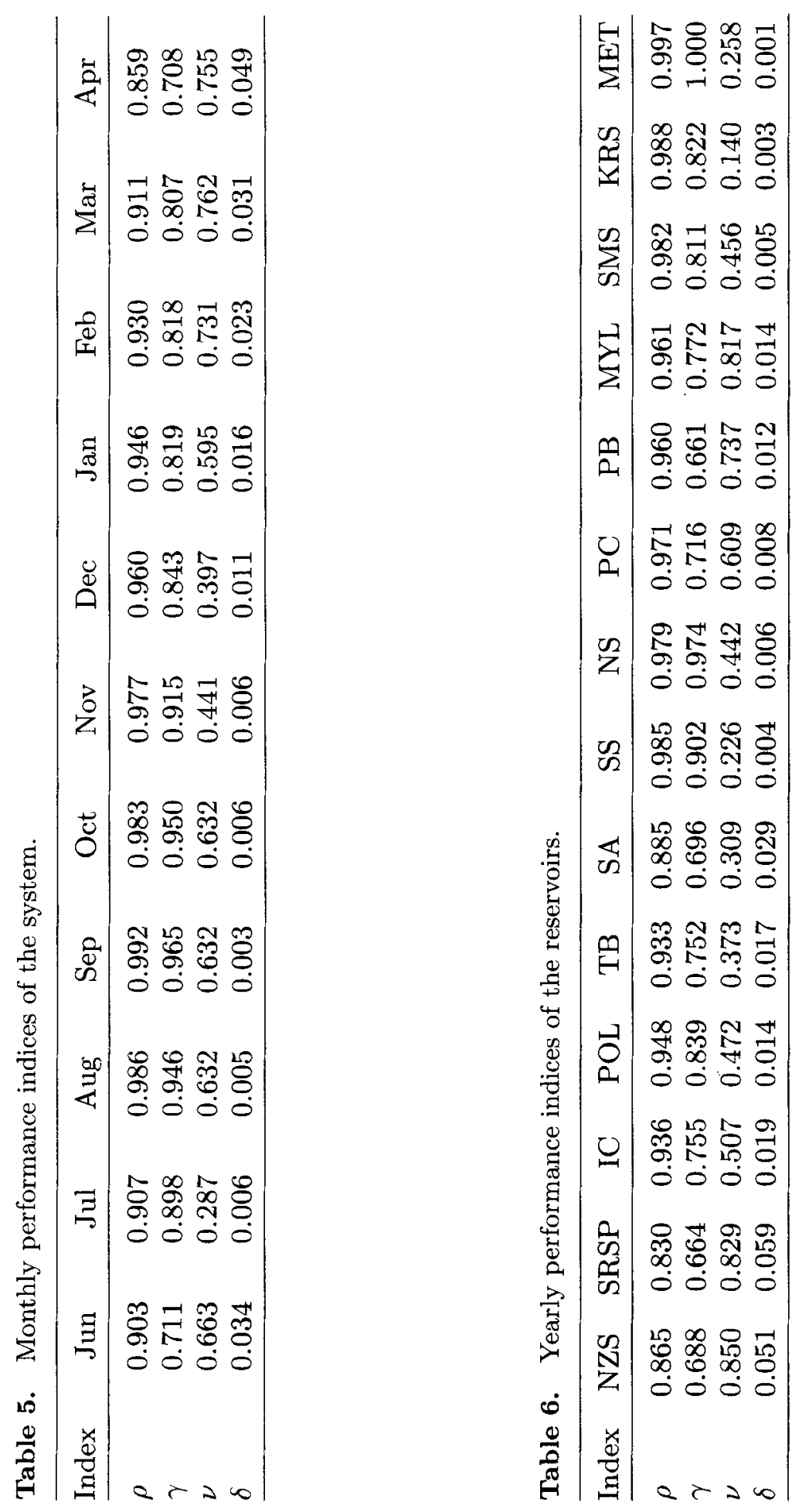
It is observed that the performance of the system can be increased to a large extent by operating the system as a single unit. If the planning is carried out with inflows at $75 \%$ probability of exceedence the existing irrigation demands can be increased to about $26 \%$. It is also observed that these demands can be satisfied with a high reliability. The study has indicated that two transfer links, the Polavaram to Prakasam Barrage and the Srisailam to Upper Anicut through Mylavaram, play a significant role in enhancing the water availability in the Cauvery and Pennar basins.

\section{List of symbols}

$\mathrm{DEF}_{t}^{\mathrm{L}}$ deficit in reservoir $\mathrm{L}$ in period $t$,

$\mathrm{DEM}_{t}^{k} \quad$ existing irrigation demand at reservoir $k$ in period $t$,

$\mathrm{DIV}_{t}^{k} \quad$ diversion from reservoir $k$ in period $t$ to meet its own demand,

$\mathrm{D}_{t}^{k} \quad$ deficit in reservoir $k$ in period $t$,

$d_{t}^{k} \quad$ water demand at reservoir $k$ in period $t$,

$F \quad$ failure index,

$I_{t}^{k} \quad$ natural inflow to reservoir $k$ in period $t$,

INCR factor by which irrigation demands are multiplied $(\geq 1.0)$,

INCR ${ }^{k}$ factor by which the monsoon irrigation demands at reservoir $k$ are multiplied $(\geq 1.0)$,

INCR $^{k}$ factor by which the nonmonsoon irrigation demands at reservoir $k$ are multiplied $(\geq 1.0)$,

$j \quad$ season index; $j=1$ for monsoon season and $j=2$ for nonmonsoon season,

$\mathrm{L} \quad$ index for the reservoir to which a release from reservoir $\mathrm{M}$ is possible,

M index for the current reservoir (reservoir from which releases and transfers are being computed),

$P \quad$ index for the reservoir to which a transfer from the reservoir $M$ is possible,

$R_{t}^{\mathrm{M}, \mathrm{L}} \quad$ release from reservoir $\mathrm{M}$ to reservoir $\mathrm{L}$ in period $t$,

$S_{1 t}^{\mathrm{M}} \quad$ storage at reservoir $\mathrm{M}$ in period $t$ after accounting for diversions and releases,

$S_{i t}^{\mathrm{k}} \quad$ storage at the beginning of period $t$ in reservoir $k$

$S_{t}^{\mathrm{L}} \quad$ storage in reservoir $\mathrm{L}$ in period $t$ after accounting for transfers and releases already committed to reservoir $L$ from reservoirs other than the reservoir $M$,

$S_{\text {MAX }}$ maximum storage,

$S_{\text {MIN }}$ minimum storage,

$S_{\text {REL }} \quad$ storage level above which a release is allowed 
$S_{\mathrm{REL}, j} \quad$ storage level at a reservoir for the season $j$ above which release from the reservoir is allowed,

$S_{\mathrm{REL}, j}^{\mathrm{M}} \quad$ storage level of reservoir $\mathrm{M}$ in season $j$, above which release from reservoir $\mathrm{M}$ is allowed,

$S_{\text {TRA }} \quad$ storage level above which a transfer is allowed,

$S_{\mathrm{TRA}, j} \quad$ storage level at a reservoir for the season $j$ above which transfer from the reservoir is allowed,

$S_{\text {TRA }, j}^{\mathrm{M}} \quad$ storage level of reservoir $\mathrm{M}$ in season $j$ above which transfer is allowed,

$t$ period index,

$T_{i} \quad$ target in period $i$,

$T_{t}^{\mathrm{M}, \mathrm{P}} \quad$ amount of water transferred from reservoir $\mathrm{M}$ to reservoir $\mathrm{P}$ in period $t$,

$U_{t}^{k} \quad$ amount of water utilised from reservoir $k$ in period $i$,

$\gamma \quad$ resiliency,

$\Delta_{i} \quad$ deficit in period $i$,

$\delta \quad$ deficit ratio,

$v \quad$ vulnerability,

$\rho$ reliability.

\section{References}

Box M J 1965 A new method of constrained optimisation and a comparison with other methods. Comput. J. 8: 42-52

Beard L R 1967 Functional evaluation of a water resources system. Int. Conf. Water for Peace, Washington DC, pp 23-31

Chaturvedi M C, Srivastava D K 1981 Study of a complex water resources system with screening and simulation models. Water Resour. Res. 17: 783-794

Chung I, Helweg O 1985 Modeling the California State Water Project. J. Water Resour. Plann. Manage, ASCE 111: 82-97

Fiering M B 1982 Estimates of resilience indices by simulation. Water Resour. Res 18: 41-50

Hashimoto T, Stedinger J R, Loucks D P 1982 Reliability, resiliency, and vulnerability criteria for water resource system performance evaluation. Water Resour. Res. 18: 14-20

Jacoby H D, Loucks D P 1972 Combined use of optimisation and simulation models in river basin planning. Water Resour. Res. 8: 1401-1414

Joeres E F, Liebman J C, Revelle C S 1971 Operating rules for joint operation of raw water sources. Water Resour. Res. 7: 225-235

Kuo J T, Hsu N S, Chu W S, Wan S, Lin Y J 1990 Realtime operation of Tanshui River reservoirs. J. Water Resour. Plann. Manage. ASCE 16: 349--361

Matalas N C 1967 Mathematical assessment of synthetic hydrology. Water. Resour. Res. 3: 937945

Ministry of Irrigation 1980 Government of India, National perspectives for water resources development. Proceedings of International Symposium on Water Resources System, University of Roorkee, Roorkee 
Razavian D, Bleed A S, Supalla R J, Gollehon N R 1990 Multistage screening process for river basin planning. J. Water. Resour. Plann. Manage., ASCE 116: 323-334

Sigvaldason O T 1976 A simulation model for operating a multipurpose multireservoir system. Water Resour. Res. 12: 263-278

Simonovic S P 1987 The implicit stochastic model for reservoir yield optimisation. Water Resour. Res. 23: $2159-2165$ 